\title{
Regional Trade and Volatility in Staple Food Markets in Africa
}

\author{
Ousmane Badiane and Sunday Odjo
}

\subsection{Introduction}

Recent studies have indicated that Africa as a whole and a number of individual countries have exhibited relatively strong trade performance in the global market (Bouët et al. 2014) as well as in continental and major regional markets (Badiane et al. 2014). The increased competitiveness has generally translated into higher shares of regional markets in total exports by the different groupings. Faster growth in demand in continental and regional markets compared to the global market has also boosted the export performance of African countries. For instance, during the second half of the last decade, Africa's share of the global export market has risen sharply, in relative terms, for all goods and agricultural products in value terms, from 0.05 to $0.21 \%$ and from 0.15 to $0.34 \%$, respectively. This is in line with the stronger competitive position of African exporters mentioned earlier.

By promoting competition and specialization in production, regional tradesimilar to global trade-can contribute to food security through its impact on long-term output and productivity growth. At the same time, it can positively affect employment and incomes. Where these effects are positive, trade increases the availability of food and improves the accessibility of food to affected segments of the population. Trade also helps reduce the unit cost of supplying food to local markets, thereby lowering food prices or reducing the pace of food price increase, which in turn improves the affordability of food. Finally, trade can also help stabilize supplies in domestic food markets and reduce the associated risks to vulnerable groups.

All of the above-mentioned benefits can be obtained, perhaps to a larger extent, through trading with the rest of the world. For instance, one could question why a

O. Badiane $(\bowtie) \cdot$ S. Odjo

International Food Policy Research Institute, 2033 K Street, NW Washington,

DC 20006-1002 USA

e-mail: ifpri@cgiar.org

(C) The Author(s) 2016 
given country should pursue an expansion of regional trade as opposed to global trade in general for stabilizing domestic food supplies, given that world production can be expected to be more stable than regional production. Several factors, such as transport costs, foreign exchange availability, responsiveness of the import sector, and dietary preferences, may provide valid economic justification for a country's efforts to boost regional trade as part of a wider supply stabilization strategy that would also include increased trade with extra-regional markets. Regional and global trade should therefore be seen as complementary rather than as substitutes.

The increase in intra-African and intra-regional trade, and the rising role of continental and regional markets as major destinations of agricultural exports by African countries suggest that cross-border trade flows will exert greater influence on the level and stability of domestic food supplies. The more countries find ways to accelerate the pace of intra-trade growth, the larger that influence is expected to be in the future. The current chapter examines the future outlook for intra-regional trade expansion and the implications for volatility of regional food markets. The chapter starts with an analysis of the potential of regional trade to contribute to stabilizing food markets, followed by an assessment of the scope for cross-border trade expansion. A regional trade simulation model is then developed and used to simulate alternative scenarios to boost trade and reduce volatility in regional markets.

\subsection{Regional Potential for the Stabilization of Domestic Food Markets Through Trade}

Variability of domestic production is a major contributor to local food price instability in low income countries. The causes of production variability are such that an entire region is less likely to be affected than individual countries. Moreover, fluctuations in national production tend to partially offset each other, so that such fluctuations are less than perfectly correlated. Food production can be expected to be more stable at regional level than at country level. In this case, expanding cross-border trade and allowing greater integration of domestic food markets would reduce supply volatility and price instability in these markets. Integrating regional markets through increased trade raises the capacity of domestic markets to absorb local price risks by: (1) enlarging the area of production and consumption and thus increasing the volume of demand and supply that can be adjusted to respond to and dampen the effects of shocks; (2) providing incentives to invest in marketing services and expand capacities and activities in the marketing sector, which raises the capacity of the private sector to respond to future shocks; and (3) lowering the size of needed carryover stocks, thereby reducing the cost of supplying markets during periods of shortage and hence decreasing the likely amplitude of price variation.

A simple comparison of the cereal production variability in individual countries against the regional average is carried out to illustrate the potential for local market stabilization through greater market integration (Badiane 1988). For that purpose, a 
trend-corrected coefficient of variation is used as a measure of production variability at both country and regional levels. We then use a normalization procedure whereby the value of the coefficient for each country is divided by the value of the coefficient for the corresponding region. Calculations are carried out for each of the three regional economic groupings (as mentioned above), and the results are presented in Table 16.6 in the annex and plotted in Fig. 16.1 a-c below. The bars in the figures represent the normalized coefficients of variation, which indicate how much more (when normalized coefficient are greater than 1) or less (when normalized coefficient are less than 1) volatile a country's production is when compared with production at the level of their respective region.

Of the three regions, SADC has the highest level of aggregate volatility with a coefficient of variation of 18.58 or more than two and three times that of ECOWAS and COMESA, respectively. For the vast majority of countries, national production volatility is considerably larger than regional level volatility. The only exceptions are the Democratic Republic of Congo (DRC) in SADC and to a lesser extent Côte d'Ivoire in ECOWAS. None of the COMESA countries has a more stable production than the regional aggregate. The COMESA countries can be divided into two subgroups: (1) a relatively low volatility subgroup with normalized coefficients of less than twice the regional average, including Burundi, Comoros, DRC, Egypt, and Uganda and (2) a high volatility regional subgroup with volatility levels that are at least five times higher than the regional level, comprising Malawi, Mauritius, ${ }^{1}$ Rwanda, Sudan, Swaziland, Zambia, and Zimbabwe. Kenya and Madagascar both have moderate levels of volatility and fall between the two groups. Most countries in SADC and ECOWAS are in the moderate regional category, with only Botswana and Mauritius (in SADC), and Gambia, Liberia, Mali, and Senegal (in ECOWAS) showing volatility levels more than three times higher than the respective regional levels. The countries in the moderate- and high-volatility subgroups would benefit the most from increased regional trade in terms of greater stability of domestic supplies.

The likelihood that a given country would benefit from the trade stabilization potential, as suggested by the difference between its volatility level and the regional average, will be greater if its production fluctuates more and is weakly correlated with that of the other countries in the region. Figure 16.2 presents the distribution of correlation coefficients between individual country's production levels for each regional group. For each country, the lower segment of the bar shows the percentage of correlation coefficients that are 0.65 or less or the share of countries with production fluctuations that are defined as relatively weakly correlated with the country's own production movements. The top segment represents the share of countries with highly correlated production fluctuations, with coefficients that are higher than 0.75 . The middle segment is the share of moderately correlated country productions, with coefficients that are between 0.65 and 0.75 .

\footnotetext{
${ }^{1}$ Mauritius has a coefficient that is more than 18 times the regional average and is not shown in the figure for clarity.
} 


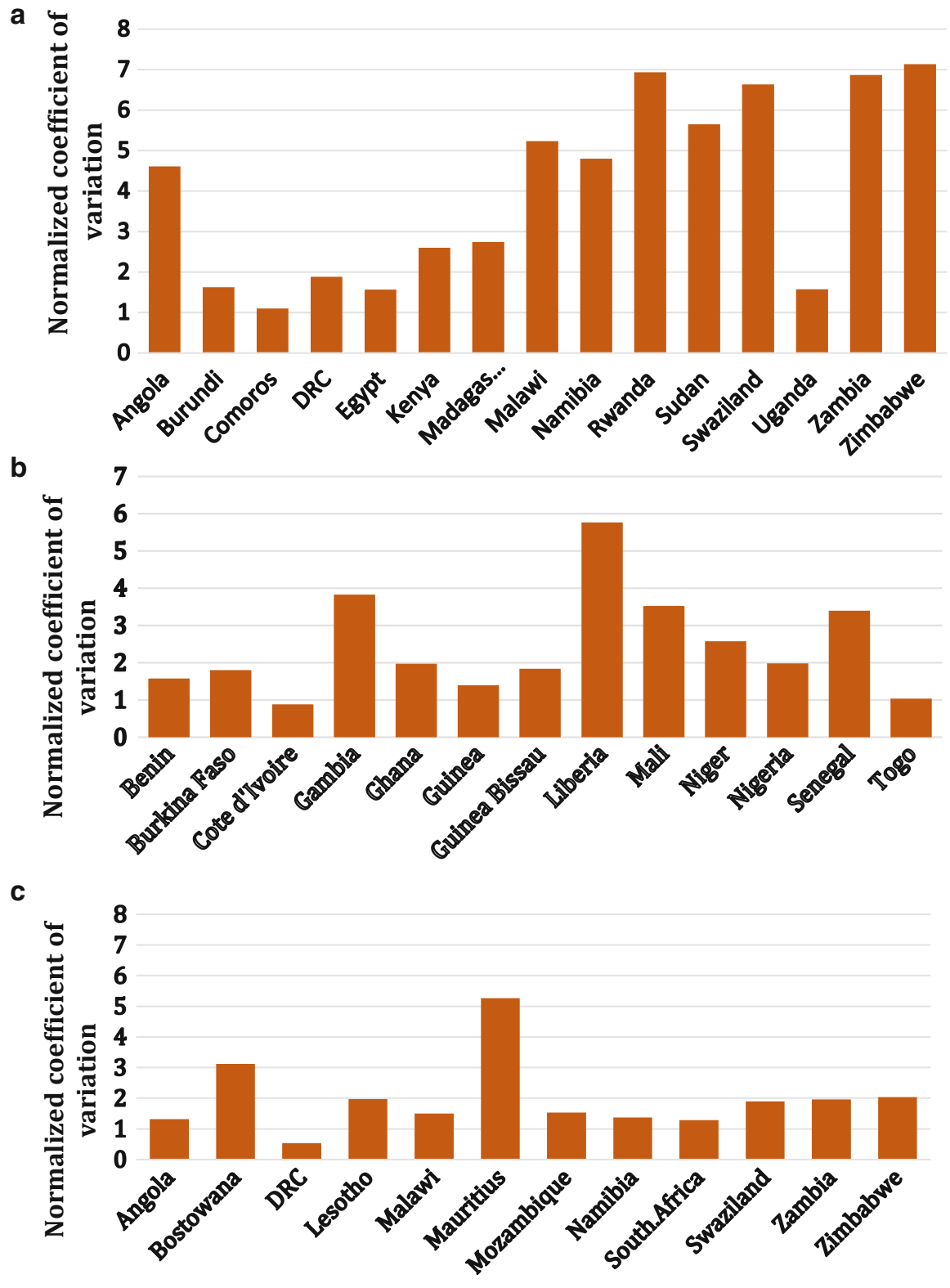

Fig. 16.1 (a) COMESA cereal production instability, 1980-2010. (b) ECOWAS cereal production instability. (c) SADC cereal production instability. Source: Authors' calculation. All graphs based on FAOSTAT 2014 data from 1980 to 2010

Using the above criteria, countries in the most volatile region, SADC, have the highest concentration of weakly correlated country production levels. As shown 

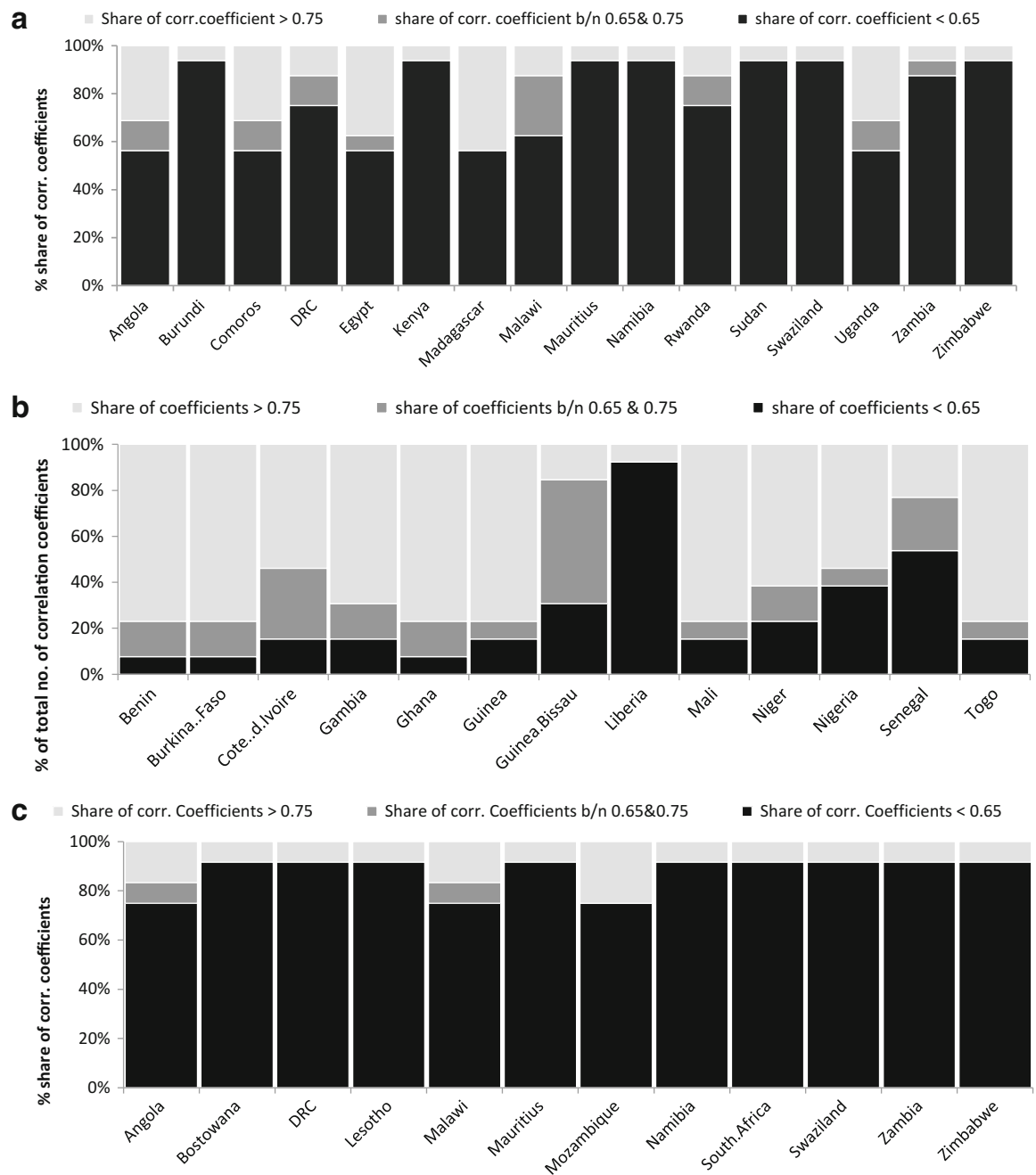

Fig. 16.2 (a) Distribution of correlation coefficients, COMESA. (b) Distribution of correlation coefficients, ECOWAS. (c) Distribution of correlation coefficients, SADC. Source: Authors' calculation. All graphs based on FAOSTAT 2014 data from 1980 to 2010

in Fig. 16.2c, only three countries have less than an $80 \%$ share of correlation coefficients below 0.65 . The combination of high volatility and weak correlation suggests that countries in this region would benefit the most from increased regional trade in terms of domestic market stabilization. They are followed by COMESA countries, where $60 \%$ of the correlation coefficients for any given country are below 0.65. In contrast, country-level production levels in the ECOWAS region tend to fluctuate more together than the other two regions, as shown by the high share of coefficients above 0.75 . The division of the region into two nearly uniform 
subregions, Sahelian and coastal, may be an explanation. In general, however, the patterns and distribution of production fluctuations among countries in all the three regions are such that increased trade could be expected to have a stabilizing effect on domestic agricultural and food markets. But that is only one condition; the other is that there is actual potential to increase cross-border trade, a question that will be examined in the next section.

\subsection{The Scope for Specialization and Regional Trade Expansion in Agriculture}

Despite the recent upward trends, the level of intra-African and intra-regional trade is still very low compared with other regions. Intra-African markets accounted only for an average $34 \%$ of the total agricultural exports from African countries between 2007 and 2011 (Badiane et al. 2014). Among the three RECs, SADC had the highest share of intra-regional trade (42\%), and ECOWAS the lowest (6\%). COMESA's share of intra-regional trade was $20 \%$. Although SADC is doing much better than the other two RECs, its member countries still account for far less than half of the value of agricultural trade within the region (Badiane et al. 2014).

There may be a host of factors behind the low levels of intra-regional trade. These factors may not only make trading with extra-regional partners more attractive, but they may also raise the cost of supplying regional markets from intra-regional sources. The exploitation of the regional stabilization potential, as pointed out above, would require measures to lower the barriers to and the bias against transborder trade such as to stimulate the expansion of regional supply capacities and of trade flows across borders. This supposes that there is sufficient scope for specialization in production and trade within the subregions. Often, it is assumed that neighboring developing countries would exhibit similar production and trading patterns because of the similarities in their resource bases, leaving little room for future specialization. There are, however, several factors that may lead to different specialization patterns among such countries. These factors include (1) differences in historical technological investments and thus the level and structure of accumulated production capacities and skills; (2) the economic distance to, and opportunity to trade with, distant markets; and (3) differences in dietary patterns as well as consumer preferences that affect the structure of local production. The different patterns of specialization in Senegal compared with the rest of Sahelian West Africa and in Kenya compared with other Eastern African countries well illustrate the influence of these factors.

Consequently, we use a series of indicators to assess the actual degree of specialization in agricultural production and trade, and whether there is real scope for transborder trade expansion as a strategy to exploit the less-than-perfect correlation between national productions to reduce the vulnerability of domestic food markets to shocks. The first two indicators are the production and export similarity indices, which measure and rank the relative importance of the production and trading of individual agricultural products in every country. The level of importance or position 
of each product is then compared for all relevant pairs of countries within each subregion. ${ }^{2}$ The indices have a maximum value of 100; an index value of 100 implies that the production or trade patterns between the considered pair of countries are completely similar. The closer the index value is to zero, the greater the degree of specialization between the two countries. Index values of around 50 and below are interpreted as indicating patterns of specialization that are compatible with higher degrees of trade expansion. The estimated indicator values for the three regional groupings, covering 150 products in total, are presented in Fig. 16.3a, b. Each bar represents the number of country pairs that falls within the corresponding range

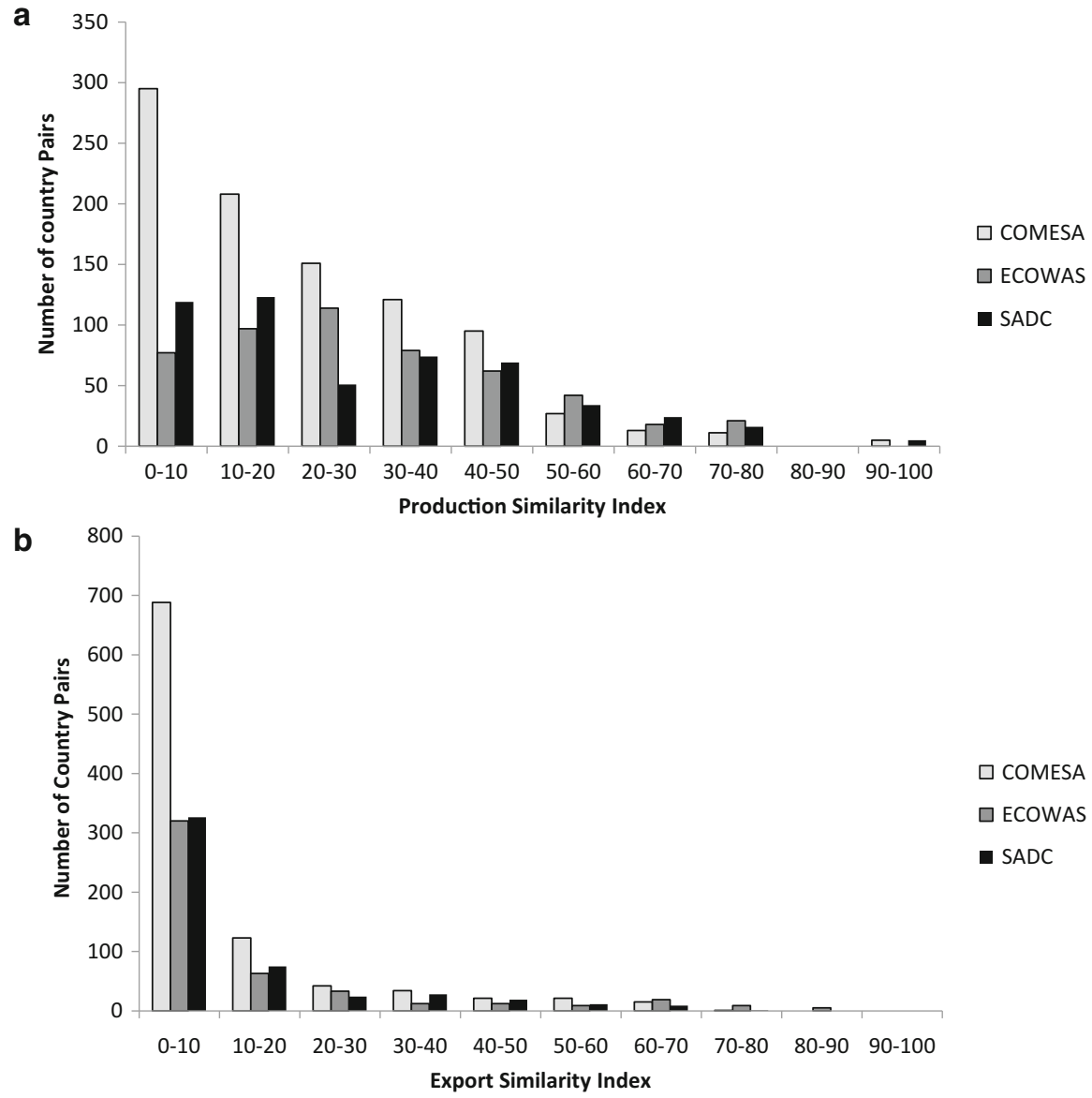

Fig. 16.3 (a) Similarity of production patterns, 2007-2011. Source: Authors' calculations based on data from FAOSTAT 2014. (b) Similarity of trading patterns, 2007-2011. Source: Authors' calculations based on data from FAOSTAT 2014

\footnotetext{
${ }^{2}$ See Koester (1986).
} 
of index values. The vast majority of country pairs fall within the $0-50$ range. A value of less than 60 is conventionally interpreted as compatible with higher trade exchange between the considered pair of countries. The estimated index values therefore suggest that there exists sufficient dissimilarity in the current production and trading patterns between countries and hence a scope for transborder trade expansion in all three subregions.

The third indicator, the revealed comparative advantage (RCA) index, is computed to further assess the degree of trade specialization among countries within the three regions. The RCA index compares the share of a given product in a given country's export basket with that of the same product in total world exports. A value greater than 1 indicates that the considered country is performing better than the world average; the higher the value is, the stronger the country's performance in exporting the considered product. Of the nearly $600 \mathrm{RCA}$ indicators estimated for various products exported by different COMESA countries, $70 \%$ have an index value higher than 1. ECOWAS and SADC each have a total of about 450 indicators. The share of indicators higher than 1 is about the same as in the case of COMESA: $68 \%$ for SADC and $73 \%$ for ECOWAS. For each regional grouping, the 20 products with the highest normalized RCA index value are presented in Table 16.1. The normalized RCA is positive for RCA indicators that are greater than 1 and negative otherwise. ${ }^{3}$ For very high RCA indicators, the normalized value tends toward 1.

All the products listed in the table have normalized RCA values above 0.98 . The rankings reflect the degree of cross-country specialization within each REC. In ECOWAS, for instance, a total of 12 products, spread across 8 out of 15 member countries, account for the highest 20 indicators for the region. There are 13 products in that category in the case of COMESA, and these products come from 9 out of 19 countries. SADC has the highest number of products in that category, a total of 14, but they come from only 5 out of 15 countries. The table also illustrates the difference in degree of specialization between the three major regions. Only two of the top ranking products (carded and combed cotton, and cashew nuts in shell) are common to the ECOWAS and SADC regions. Even between COMESA and SADC, only six of the top ranking products are common to the two regions, while there are no common top ranking products between COMESA and ECOWAS. A fuller appreciation of the degree of specialization across all countries in the three regions is best obtained by looking at the RCA values for the entire set of products and countries. For instance, if countries have similar patterns of specialization, the same products would tend to rank equally high and the values of the RCA indicator for the same product would not vary significantly across countries. Similarly, if countries have similar patterns of specialization, exports would be concentrated around a few products, with substantial variation of the indicator value across products. An analysis of the variance of the RCA index is, therefore, carried out to test for either of the above-mentioned possibilities. The results of the analysis, presented in Table 16.2, show that for the entire sample of African countries, nearly two-thirds

\footnotetext{
${ }^{3}$ The formula for the normalized RCA is $(\mathrm{RCA}-1) /(\mathrm{RCA}+1)$.
} 


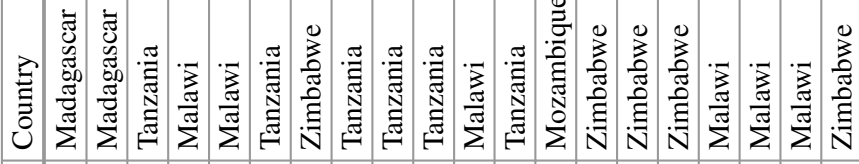

클

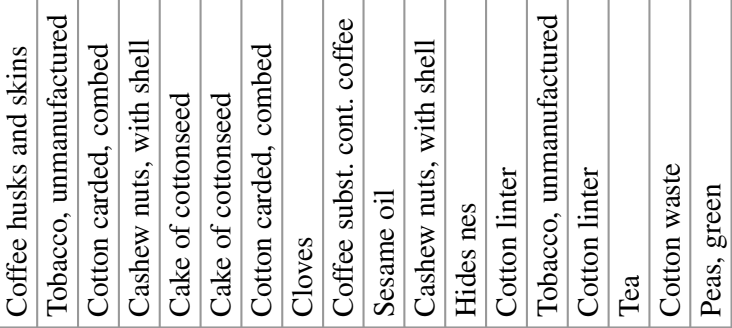

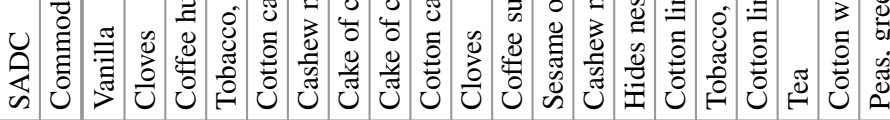

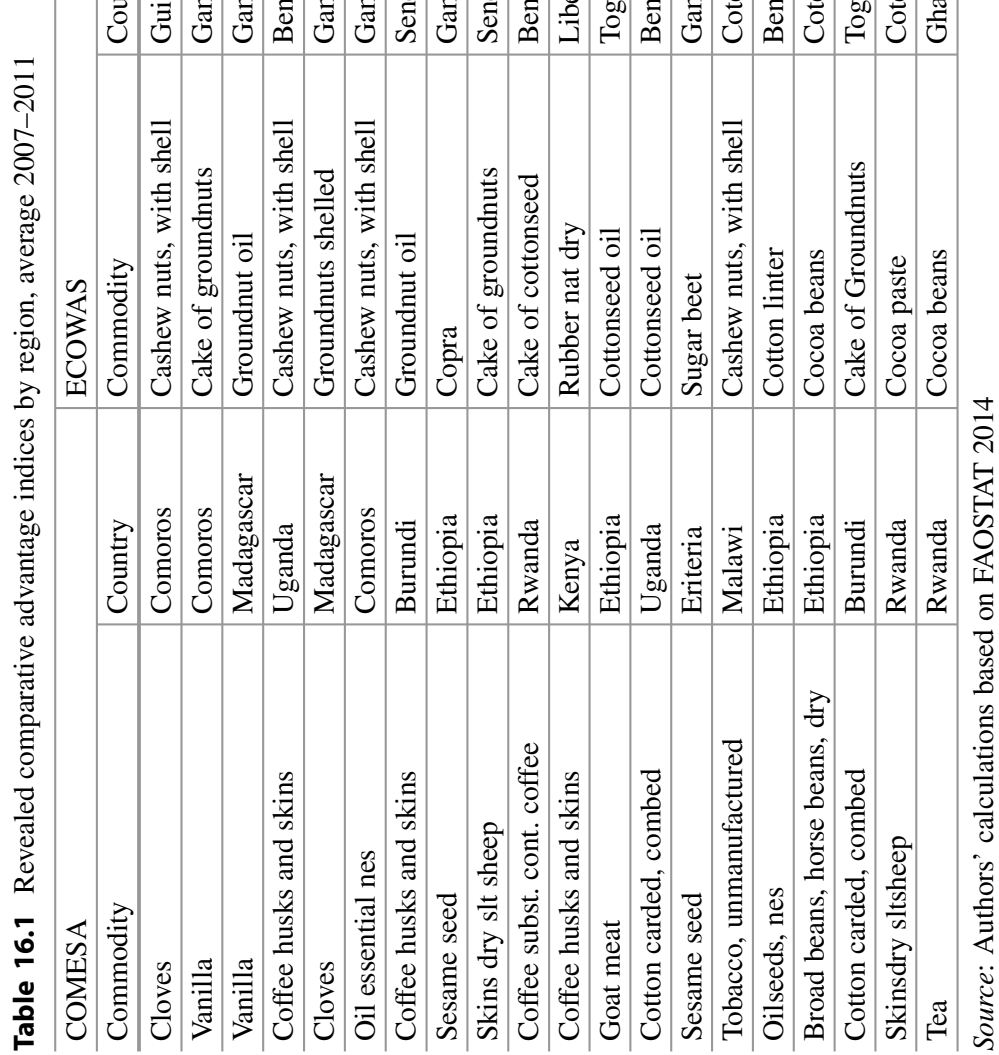


Table 16.2 Estimation of RCA variability across countries and products

\begin{tabular}{c|l|l|l|l|l}
\hline Source of variance & $\begin{array}{l}\text { Sequential } \\
\text { sum of square }\end{array}$ & Mean squared & $F$ & $P$-value & $\begin{array}{l}\text { Share of variation } \\
\text { explained }\end{array}$ \\
\hline Model & 1489.66 & 6.03 & 46.63 & 0.00 & $72.86 \%$ \\
\hline Country & 936.94 & 23.42 & 181.09 & 0.00 & $45.82 \%$ \\
\hline Commodity & 552.44 & 2.68 & 20.73 & 0.00 & $27.02 \%$ \\
\hline Year & 0.28 & 0.28 & 2.19 & 0.14 & $0.01 \%$ \\
\hline Residual & 555.03 & 0.129 & & & $27.14 \%$ \\
\hline Total & 2044.69 & 0.45 & & & \\
\hline Number of obs. & 4539 & $R^{2} 0.73$ & $R^{2}$ adj 0.71 & &
\end{tabular}

Note: The mean square (partial sum of squares/degrees of freedom) is used to compute the $F$-statistic and determine the significant amounts of variation. This ANOVA is without interaction terms due to the missing values from the unbalanced nature of the data. The time factor is included

(63\%) of the total variation of the RCA index among countries and commodities is accounted for by country-to-country variation. The balance of variation is explained by variation across products. The RCA index, like the previous two indicators, thus confirms the existence of dissimilar patterns of trade specialization in agricultural products.

So far, the analysis has established the existence of dissimilar patterns of specialization in production and trade of agricultural products among countries within and across the three major regions. Two final indicators, the Trade Overlap Indicator (TOI) and the Trade Expansion Indicator (TEI), are calculated to examine the potential to expand trade within the three blocks of countries based on current trade patterns.

The indicators measure how much of the same product a given country or region exports and imports at the same time. The TOI measures the overall degree of overlapping trade flows for a country or region as a whole, while the TEI measures the overlapping trade flows at the individual product level for a country or region. The results are presented in Fig. 16.4 and Table 16.3. The results indicate that there is a considerable degree of overlapping trade flows: $25 \%$ for Africa as a whole and as much as $40 \%$ for the SADC region. Normalized TOI values, obtained by dividing country TOI values by the TOI value, for the respective regions can be found in Badiane et al. (2014). In the vast majority of cases, they are significantly less than 1 . The overlapping regional trade must therefore be taking place between different importing and exporting countries. In other words, some countries are exporting (importing) the same products that are being imported (exported) by other member countries in their respective grouping, but in both cases to and from countries outside the region. By redirecting such flows, countries should be able to expand transborder trade within their groupings.

The TEI indicates which products have the highest potential for increased transborder trade based on the degree of overlapping trade flows. Table 16.3 lists the 20 products with the highest TEI value for each of the three regions. The lowest TEI value for any of the products across the three regions is 0.41 . RCA values 


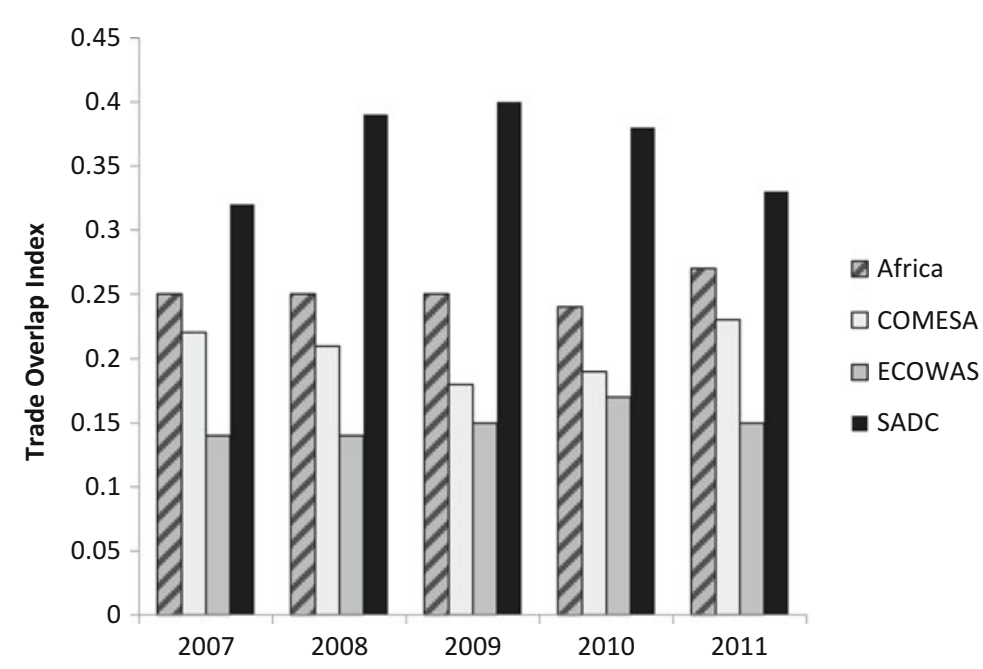

Fig. 16.4 Trade overlap indicators, average 2007-2011. Source: Authors' calculations based on FAOSTAT 2014

for the same products presented in Badiane et al. (2014) are all greater than 1, except for only three products: fresh fruits in ECOWAS, bananas in COMESA, and chocolate products in SADC. The fact that products with high TEI also have high RCA indicator values point to a real scope for transborder trade expansion in all three subregions.

The findings above indicate a real potential to expand intra-trade in all three regions beyond the levels shown in Table 16.1, even with current production and trade patterns. The remainder of the chapter therefore analyzes the outlook for intratrade expansion and the expected impact of volatility of regional food markets over the next 15 years. This is done by simulating alternative policy scenarios to boost intra-regional trade and by comparing the resulting effect on the level and volatility of trade flows up to 2025 with outcomes simulated under a baseline scenario that assumes continuation of historical trends. 
$\stackrel{\frac{0}{3}}{\frac{2}{2}}$

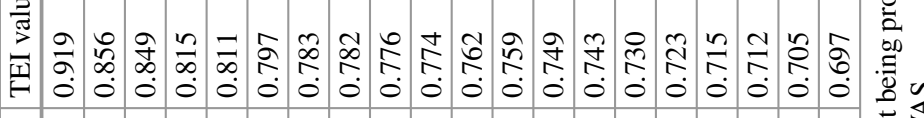

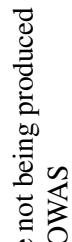

क्षे

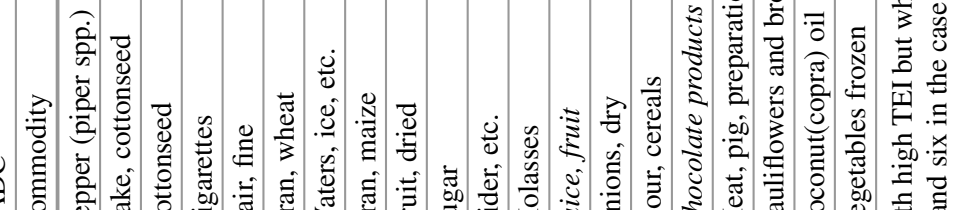

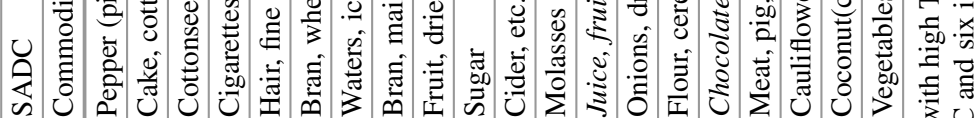

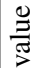
造

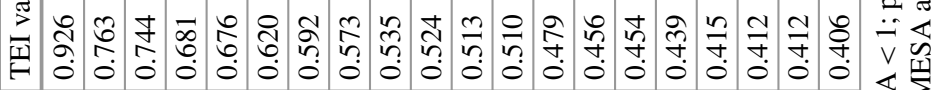
2
0

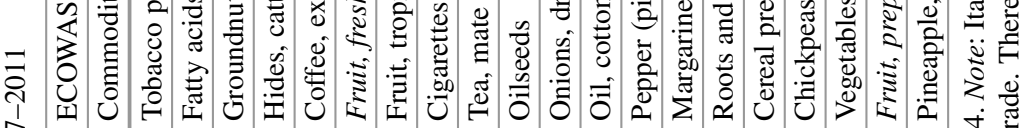

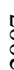
\&

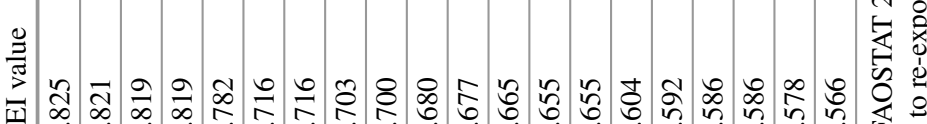

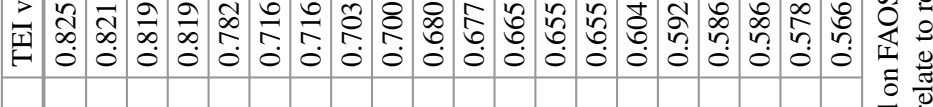

:

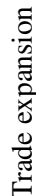

离

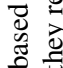

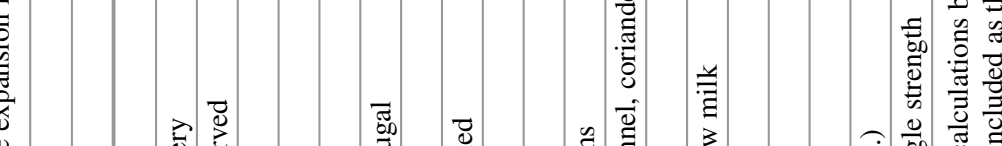

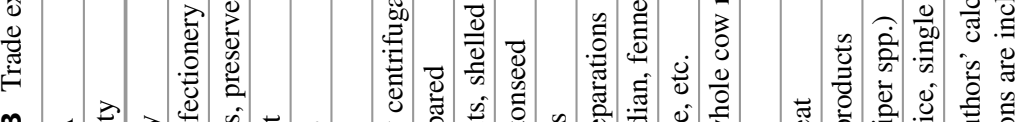
m.

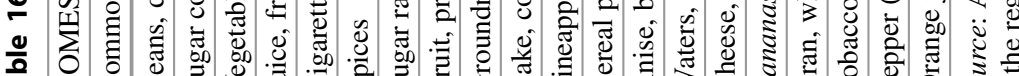
荥 


\subsection{The Outlook for Regional Cross-Border Trade and Market Volatility Under Alternative Scenarios}

The preceding analysis presents evidence that African countries could use increased regional trade to enhance the resilience of domestic markets to supply shocks. The high cost of moving goods across domestic and transborder markets and outwardly biased trading infrastructure are major determinants of the level and direction of trade among African countries. A strategy to exploit the regional stabilization potential therefore has to include measures to lower the general cost of trading and remove additional barriers to cross-border trade. This section simulates the impact of such changes on regional trade flows, using IFPRI's regional Economy-wide Multimarket Model (EMM) described below. ${ }^{4}$

\subsubsection{The Regional Trade Simulation Model}

In this study, the original EMM was modified to differentiate between intra- and extra-regional trade sources and destinations and between informal and formal trade costs in intra-regional trade transactions. In its original version, the EMM solves for optimal levels of supply $\mathrm{QX}_{r c}$, demand $\mathrm{QD}_{r c}$ and net trade (either import $\mathrm{QM}_{r c}$ or export $\mathrm{QE}_{r c}$ ) of different commodities $c$ for individual member countries $r$ of the modeled region.

Supply and demand balance at the national level determines domestic output prices $\mathrm{PX}_{r c}$ as stated by Eq. (16.1), while Eq. (16.2) connects domestic market prices $\mathrm{PD}_{r c}$ to domestic output prices, taking into account an exogenous domestic marketing margin $\operatorname{mar} g D_{r c}$. The net trade of a commodity in a country is determined through mixed complementarity relationships between producer prices and potential export quantities and between consumer prices and potential import quantities. Accordingly, Eq. (16.3) ensures that a country will not export a commodity $\left(\mathrm{QE}_{r, c}=0\right)$ as long as the producer price of that commodity is higher than its export parity price, where pwe ${ }_{r c}$ is the country's FOB price and $\operatorname{marg} W_{r c}$ is an exogenous trade margin accounting for the cost of moving the commodity to and from the border. If the domestic market balance constraint in Eq. (16.1) requires that the country exports some excess supply of a commodity $\left(\mathrm{QE}_{r, c}>0\right)$, then the producer price will be equal to the export parity price of that commodity. Additionally, Eq. (16.4) governs any country's possibility to import a commodity, where $\mathrm{pwm}_{r c}$ is its CIF price. There will be no import $\left(\mathrm{QM}_{r, c}=0\right)$ as long as the import parity price of a commodity is higher than its domestic consumer price. The domestic market balance constraint requires that, if a country has to import a commodity to meet a given excess demand $\left(\mathrm{QM}_{r, c}>0\right)$, then the domestic consumer price will be equal to the import parity price of that commodity.

\footnotetext{
${ }^{4}$ See Diao et al. (2007) and Nin-Pratt et al. (2011).
} 


$$
\begin{aligned}
& \mathrm{QX}_{r c}+\mathrm{QM}_{r c}-\mathrm{QE}_{r c}=\mathrm{QD}_{r c} \\
& \mathrm{PX}_{r c} \cdot\left(1+\operatorname{mar} g D_{r c}\right)=\mathrm{PD}_{r c} \\
& \mathrm{PX}_{r c} \geq \mathrm{pwe}_{r c} \cdot\left(1-\operatorname{marg} W_{r c}\right) \perp \quad \mathrm{QE}_{r, c} \geq 0 \\
& \operatorname{pwm}_{r c} \cdot\left(1+\operatorname{marg} W_{r c}\right) \geq \mathrm{PD}_{r c} \quad \perp \quad \mathrm{QM}_{r, c} \geq 0
\end{aligned}
$$

In the version of the EMM used in this study, the net export of any commodity is modeled as an aggregate of two output varieties differentiated by their market outlets (regional and extra-regional) while assuming an imperfect transformability between the two export varieties. Similarly, the net import of any commodity is modeled as a composite of two varieties differentiated by their origins (regional and extra-regional) while assuming an imperfect substitutability between the two import varieties.

In order to implement export differentiation by destination, the mixed complementarity relationship in Eq. (16.3) is replaced with two new equations which specify the price conditions for export to be possible to both destinations. Equation (16.5) indicates that for export to extra-regional market outlets to take place $\left(\mathrm{QEZ}_{r c}>0\right)$, suppliers should be willing to accept a price $\mathrm{PEZ}_{r c}$ that is not greater than the export parity price when exporting to that destination. Similarly, Eq. (16.6) ensures that exporting to within-region market outlets is possible $\left(\mathrm{QER}_{r c}>0\right)$ only if suppliers are willing to receive a price $\mathrm{PER}_{r c}$ that is not more than the regional market clearing price $\mathrm{PR}_{\mathrm{c}}$ adjusted downward to account for exogenous regional trade margins $\operatorname{mar} g R_{r c}$ incurred in moving the commodity from the farm gate to regional market (see Eq. (16.17) below for the determination of $\mathrm{PR}_{\mathrm{c}}$ ).

$$
\begin{aligned}
\mathrm{PEZ}_{r c} \geq \mathrm{pwe}_{r c} \cdot\left(1-\operatorname{marg} W_{r c}\right) & \perp & \mathrm{QEZ}_{r c} \geq 0 \\
\mathrm{PER}_{r c} \geq \mathrm{PR}_{\mathrm{c}} \cdot\left(1-\operatorname{mar} g R_{r c}\right) & \perp & \mathrm{QER}_{r c} \geq 0
\end{aligned}
$$

Subject to these price conditions, Eqs. (16.7)-(16.10) determine the aggregate export quantity and its optimal allocation to alternative destinations. Equation (16.7) indicates that the aggregate export of a commodity by individual countries $\mathrm{QE}_{r c}$ is obtained through a constant elasticity of transformation (CET) function of the quantity $\mathrm{QEZ}_{r c}$ exported to extra-regional market outlets and the quantity $\mathrm{QER}_{r c}$ exported to intra-regional market outlets, where $\rho_{r c}^{e}, \delta_{r c}^{e}$, and $\alpha_{r c}^{e}$ are the CET function exponent, share parameter, and shift parameter, respectively. Equation (16.8) is the first-order condition of an aggregate export revenue maximization problem, given the prices that suppliers can receive for the different export destinations and subject to the CET export aggregation function. The equation indicates that an increase in the ratio of intra-regional to extra-regional prices will increase the ratio of intra-regional to extra-regional export quantities (i.e., exports shift toward 
destinations which offer higher returns). Equation (16.9) helps identify the optimal quantities supplied to each destination; it states that aggregate export revenue at producer price of export $\mathrm{PE}_{r c}$ is the sum of export sales revenues from both intraregional and extra-regional market outlets at supplier prices, while Eq. (16.10) sets the producer price of export to be the same as the domestic output price $\mathrm{PX}_{r c}$, which is determined by the supply and demand balance equation (Eq. 16.1) as earlier explained.

$$
\begin{gathered}
\mathrm{QE}_{r c}=\alpha_{r c}^{e} \cdot\left(\delta_{r c}^{e} \cdot \mathrm{QER}_{r c}^{\rho_{r c}^{e}}+\left(1-\delta_{r c}^{e}\right) \cdot \mathrm{QEZ}_{r c}^{\rho_{r c}^{e}}\right)^{\frac{1}{\rho_{r c}}} \\
\frac{\mathrm{QER}_{r c}}{\mathrm{QEZ}_{r c}}=\left(\frac{\mathrm{PER}_{r c}}{\mathrm{PEZ}_{r c}} \cdot \frac{1-\delta_{r c}^{e}}{\delta_{r c}^{e}}\right)^{\frac{1}{\rho_{r c}-1}} \\
\mathrm{PE}_{r c} \cdot \mathrm{QE}_{r c}=\mathrm{PER}_{r c} \cdot \mathrm{QER}_{r c}+\mathrm{PEZ}_{r c} \cdot \mathrm{QEZ}_{r c} \\
\mathrm{PE}_{r c}=\mathrm{PX}_{r c}
\end{gathered}
$$

Import differentiation by origin is implemented by following the same procedure for export differentiation by destination, as described above. Equation (16.4) is replaced by Eqs. (16.11) and (16.12). Accordingly, import from extra-regional origins will happen $\left(\mathrm{QMZ}_{r, c}>0\right)$ only if domestic consumers are willing to pay a price $\mathrm{PMZ}_{r c}$ that is not smaller than the import parity price for the extra-regional variety. Furthermore, import from intra-regional origins is possible $\left(\mathrm{QMR}_{r, c}>0\right)$ only if domestic consumers are willing to pay at a price $\mathrm{PMR}_{r c}$ that is not smaller than the regional market clearing price $\mathrm{PR}_{\mathrm{c}}$ adjusted upward to account for exogenous regional trade margins $\operatorname{mar} g R_{r c}$ incurred in moving the commodity from the regional market to consumers.

$$
\begin{array}{ccc}
\operatorname{pwm}_{r c} \cdot\left(1+\operatorname{mar} g W_{r c}\right) \geq \mathrm{PMZ}_{r c} & \perp & \mathrm{QMZ}_{r, c} \geq 0 \\
\mathrm{PR}_{r} \cdot\left(1+\operatorname{mar} g R_{r c}\right) \geq \mathrm{PMR}_{r c} & \perp & \mathrm{QMR}_{r c} \geq 0
\end{array}
$$

Under these price conditions, Eq. (16.13) represents aggregate import quantity $\mathrm{QM}_{r c}$ as a composite of intra- and extra-regional import variety quantities $\mathrm{QMR}_{r c}$ and $\mathrm{QMZ}_{r}$, respectively, using a constant elasticity of substitution (CES) function; in the equation, the terms $\rho_{r c}^{m}, \delta_{r c}^{m}$, and $\alpha_{r c}^{m}$ stand for the CES function exponent, share parameter, and shift parameter, respectively. The optimal mix of the two varieties is defined by Eq. (16.14), which is the first-order condition of an aggregate import cost minimization problem, subject to the CES aggregation (Eq. 16.13) and given import prices from both origins. An increase in the ratio of extra-regional to intra-regional import prices will increase the ratio of intra-regional to extra-regional import quantities (i.e., imports shift away from more expensive sources). Equation (16.15) identifies the specific quantities imported from each origin. It defines the total import cost at consumer price of import $\mathrm{PM}_{r c}$ as the sum of intra-regional and 
extra-regional import costs, while Eq. (16.16) sets the consumer price of import to be the same as the domestic market price $\mathrm{PD}_{r c}$, which is determined by Eqs. (16.1) and (16.2), as earlier explained

$$
\begin{gathered}
\mathrm{QM}_{r c}=\alpha_{r c}^{m} \cdot\left(\delta_{r c}^{m} \cdot \mathrm{QMR}_{r c}^{-\rho_{r c}^{m}}+\left(1-\delta_{r c}^{m}\right) \cdot \mathrm{QMZ}_{r c}^{-\rho_{r c}^{m}}\right)^{-\frac{1}{\rho_{r c}^{m}}} \\
\frac{\mathrm{QMR}_{r c}}{\mathrm{QMZ}_{r c}}=\left(\frac{\mathrm{PMZ}_{r c}}{\mathrm{PMR}_{r c}} \cdot \frac{\delta_{r c}^{m}}{1-\delta_{r c}^{m}}\right)^{\frac{1}{1+\rho_{r c}^{m}}} \\
\mathrm{PM}_{r c} \cdot \mathrm{QM}_{r c}=\mathrm{PMR}_{r c} \cdot \mathrm{QMR}_{r c}+\mathrm{PMZ}_{r c} \cdot \mathrm{QMZ}_{r c} \\
\mathrm{PM}_{r c}=\mathrm{PD}_{r c}
\end{gathered}
$$

After determining export quantities and prices by destination, and import quantities and prices by origin, the regional market clearing price $\mathrm{PR}_{\mathrm{c}}$ can now be solved. Equation (16.17) imposes the regional market balance constraint by equating the sum of intra-regional export supplies to the sum of intra-regional import demands, with $q d s t k_{c}$ standing for discrepancies existing in observed aggregate intra-regional export and import quantity data in the model's base year. Thus, $\mathrm{PR}_{\mathrm{c}}$ is the price that ensures regional market balance.

$$
\sum_{r} \mathrm{QER}_{r c}=\sum_{r} \mathrm{QMR}_{r c}+q d s t k_{c}
$$

The model is calibrated separately for each of the three RECs. Calibration is performed such that for every member country within each REC, the same production, consumption, and net trade data are replicated as observed for different agricultural subsectors and two nonagricultural subsectors in 2007-2008. Baseline trend scenarios are then constructed such that until 2025, changes in crop yields, cultivated areas, outputs, and GDP reflect the same observed changes. Table 16.6 in the annex compares the calibrated agricultural and economy-wide GDP growth rates under the baseline scenario with the observed rates in the recent years. Although the model is calibrated to the state of national economies 7 years earlier, it closely reproduces the countries' current growth performances.

Four different scenarios are simulated using the EMM. The first is the baseline scenario described above, which assumes a continuation of current trends up to 2025. It is used later as a reference to evaluate the impact of the changes under the remaining three scenarios. The latter scenarios introduce the following three different sets of changes to examine their impacts on regional trade levels: a reduction of $10 \%$ in the overall cost of trading in every country; removal of all crossborder trade barriers-that is, a reduction of their tariff equivalent to zero; and a $10 \%$ yield increase across the board. These changes are modeled to take place between 2008 (the base year) and 2025. The change in cross-border exports is used as an indicator of the impact on intra-regional trade. In the original data, there are large discrepancies between recorded regional exports and import levels, the value of the 
latter often being multiples of the former. The more conservative export figures are therefore the preferred indicator of intra-regional trade.

\subsubsection{Intra-trade Simulation Results}

The results for the different regions are presented in Figs. 16.5 and 16.6. Figure 16.5 presents the results of the baseline scenarios for the three regions from 2008 to 2025. Assuming the current trends to continue, intra-regional trade in both ECOWAS and SADC is expected to expand rapidly but with marked differences between crops. The aggregate volume of intra-regional trade in staples would approach 3 million tons in the case of ECOWAS and about half of that amount in the case of SADC if the growth rates in yields, cultivated areas, and nonagricultural income sustained at their current level until 2025. Cereals would see the smallest gains, while trade in roots and tubers as well as other food crops would experience much faster growth in the case of ECOWAS. This is in line with the current structure of and trends in commodity demand and trade. While the increase in demand for roots and tubers is being met almost exclusively using local sources, the fast growing demand for cereals is heavily tilted toward rice, which is supplied from outside the region. The two leading cereals that are traded regionally, maize and millet, therefore benefit less from the expansion of regional demand and have historically seen slower growth in trade than roots and tubers. In the case of SADC, the rise of Angola as a main exporter of roots and tubers starting in 2013 is a main factor in explaining the strong boost in regional trade of that commodity. Zimbabwe had been the sole exporter of roots and tubers before 2013 and exported only very modest quantities. Hence, the high rates of growth of overall regional exports can be attributed to the developments in Angola.

The story is a bit different in the case of COMESA. As was already made apparent by the market share analysis earlier, the COMESA regional market has been the least dynamic of the three regional markets and the only one associated with a negative market effect. COMESA is the only region where the member countries have experienced a decline in competitiveness as a whole. The underwhelming performance is reflected in the baseline scenario. If current trends were to continue, the levels of intra-regional trade would continue to stagnate, except in the case of cereals. And even for this group of products, the decline in trade volumes would be reversed, but the reversal would not be enough to bring the trade volumes back to their initial levels. The projected evolution of the trade in cereals reflects different country dynamics and a shift in the sources of regional exports. The fall in regional trade levels at the beginning of the period is a result of a continual decline in exports from the two main traditional suppliers Egypt and Malawi. At the same time, the faster growth in several other countries, particularly Tanzania and Ethiopia, results in rising exports from these countries, starting from 2011 for Tanzania and from 2019 for Ethiopia. The result is a U-shaped pattern in COMESA cereals exports: the declining exports in some countries are eventually offset by the increasing imports in other countries. The graphs in Fig. 16.6 show the cumulated changes in intra- 


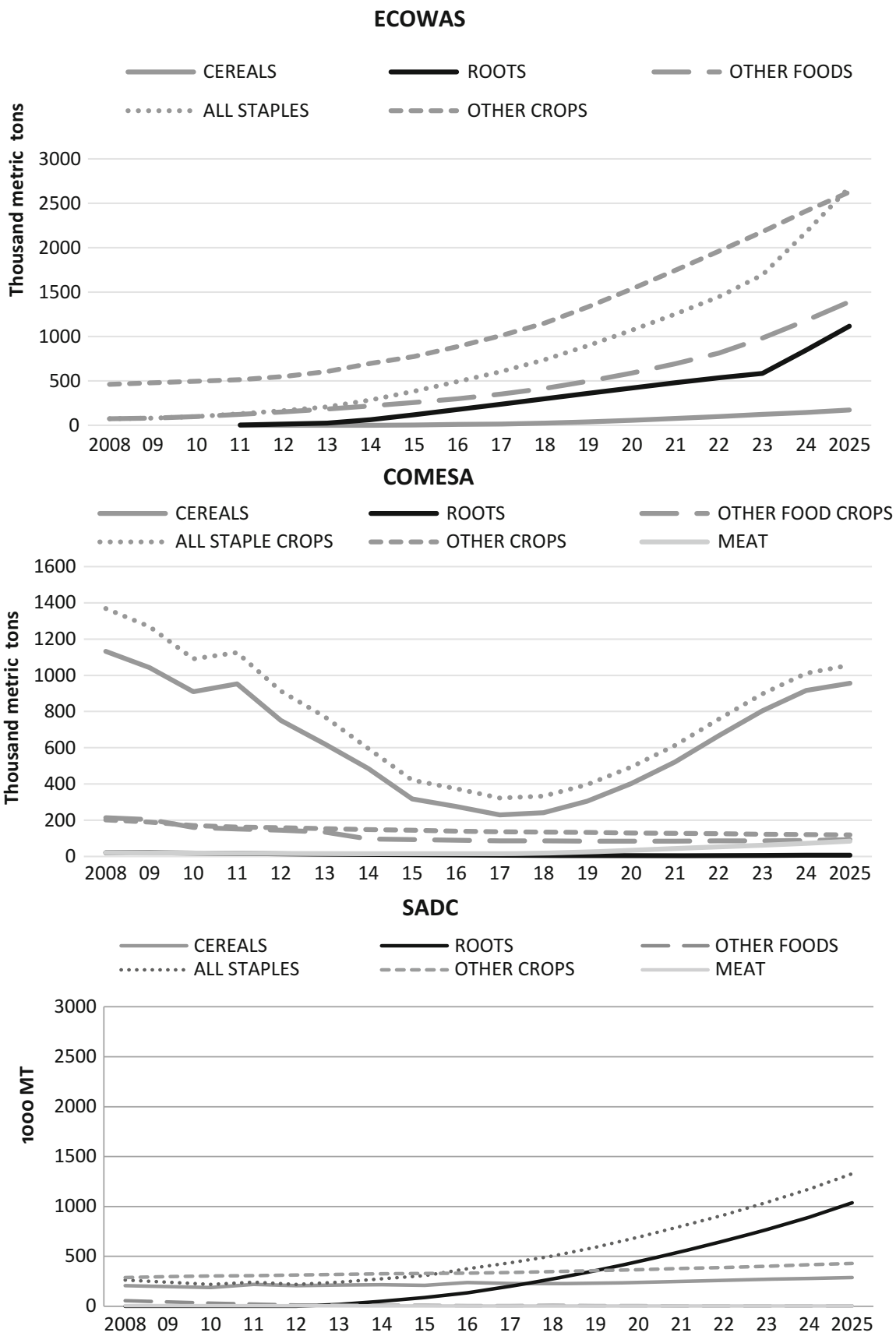

Fig. 16.5 Regional exports outlook, baseline. Source: Authors' calculation 

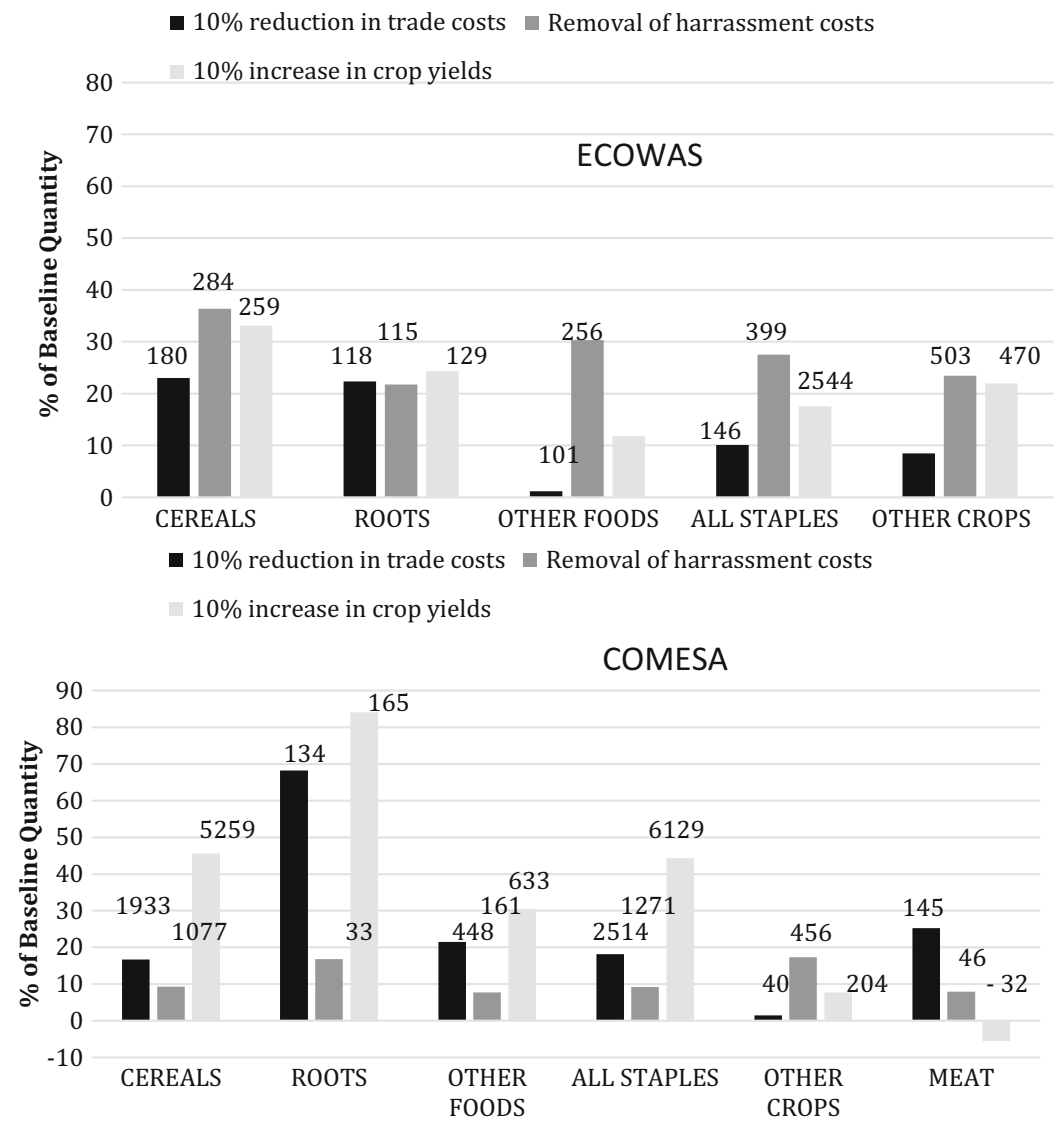

- $10 \%$ reduction in trade costs $\quad$ Removal of harrassment costs

$10 \%$ increase in crop yields

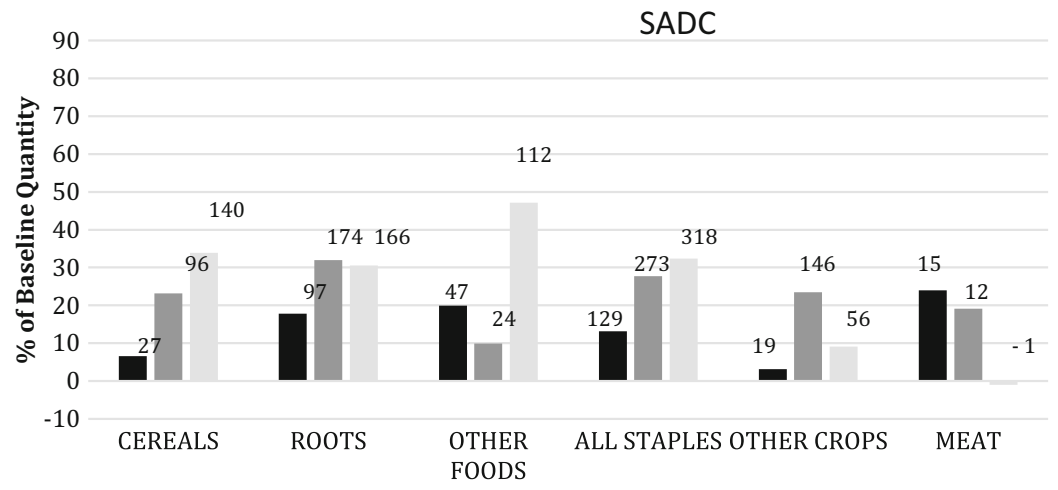

Fig. 16.6 Changes in cost, yields, and exports. Source: Authors' calculation. Note: Figures above the bars indicate cumulative increases in regional export supply in $1000 \mathrm{mt}$. Other crops include all or subset of the following crops: fruits and vegetables, cotton, sugar, cocoa, coffee, tea, tobacco, spices, and nuts 
regional export levels by 2025 compared with the baseline results; the changes are the result of a reduction in total trading cost, removal of transborder trade barriers, and a yield increase. The bars represent the percentage changes, and the numbers above the bars indicate the corresponding absolute changes in 1000 metric tons. The results show that intra-regional trade invariably increases by a considerable margin for cereals and roots and tubers (the main food crops) in response to changes in trading costs and yields. Intra-community trade levels in ECOWAS climb by between 10 and $35 \%$ for most products over the entire period. By 2025, when compared to baseline trends, the volume of cereal trade increases by a cumulative total of between 200,000 and 300,000 $\mathrm{mt}$ for individual products and the volume of overall staple trade by between 1.5 and 4.0 million tons. Cereals seem to respond better than other products in general. It also appears that removing transborder trade barriers would have the strongest impact of trade flows across the board.

The COMESA region shows similar increases in overall trade in staples. Cereals trade tends to be proportionally less responsive but because of its initial higher levels, the cumulative additional volume of regional trade is much higher, ranging from 0.7 million to more than 3.0 million tons above the baseline. Also, in contrast to ECOWAS, intra-regional trade in COMESA seems to be more responsive to changes in overall trading costs and yields than to changes in cross-border barriers. This may be explained by the fact that equivalent tariffs constitute a smaller fraction of producer prices, and hence changes in barriers result in smaller changes in incentives. Trade in the SADC region also seems to respond more to changes in transborder trade barriers and yields, as in the case of ECOWAS. A $10 \%$ increase in yields would raise trade in staples by a cumulative volume of slightly more than 3.0 million tons by 2025 compared to the baseline scenario.

\subsubsection{Regional Market Volatility Under Alternative Policy Scenarios}

Under each scenario, the model-simulated quantities of intra-regional exports $\mathrm{QER}_{r c}$ are used to estimate an index of future export volatility at country and regional level as follows: First, a trend-corrected coefficient of variation TCV is calculated for each country, using the following formula as in Cuddy and Della Valle (1978):

$$
\mathrm{TCV}=\mathrm{CV} \cdot \sqrt{\left(1-\overline{R^{2}}\right)}
$$

where $\mathrm{CV}$ is the coefficient of variation and $\overline{R^{2}}$ is the adjusted coefficient of determination of the linear trend regression obtained using the time series of aggregate quantities of intraregional exports of all staple food crops from 2008 to 2025. 
Second, an index of regional volatility $\mathrm{TCV}_{\mathrm{REC}}$ is derived for each $\mathrm{REC}$ as a weighted average of trend-corrected coefficients of variation of its member countries with the formula

$$
\mathrm{TCV}_{\mathrm{REC}}^{2}=\sum_{i}^{n} s_{i}^{2} \cdot \mathrm{TCV}_{i}^{2}+2 \sum_{i}^{n} \sum_{j}^{n} s_{i} \cdot s_{j} \cdot v_{i j} \cdot \mathrm{TCV}_{i} \cdot \mathrm{TCV}_{j}
$$

where $\mathrm{TCV}_{i}$ and $\mathrm{TCV}_{j}$ are the trend-corrected coefficients of variation in aggregate exports of staple food crops in countries $i$ and $j, n$ is the number of member countries in the REC, $s_{i}$ and $s_{j}$ are the shares of countries $i$ and $j$ in the region's overall intra-regional exports of staple food crops, and $v_{i j}$ is the coefficient of correlation between aggregate exports of countries $i$ and $j$. Finally, the coefficients of variation at country level are normalized by dividing them by the respective regional coefficients.

The historical and simulated levels of cross-border trade volatility of food staples in the various regions are reported in Table 16.4. The volatility levels simulated under historical trends are calculated based on the TradeMaps database. ${ }^{5}$ Table 16.5 shows the comparison of the simulated volatility levels under the various alternative scenarios with historical volatility levels, with the difference expressed in absolute point changes. The figures in the two tables show that volatility levels are lower under nearly all scenarios than under historical trends. The only exception is in the case of ECOWAS, where regional cross-border trade volatility decreases with a reduction of overall trading costs, but it rises when cross-border trade barriers

Table 16.4 Regional cross-border trade volatility under various scenarios

\begin{tabular}{l|l|l|l|l|l}
\hline & $\begin{array}{l}\text { Historical } \\
\text { trend } \\
(1996-2012)\end{array}$ & $\begin{array}{l}\text { Baseline } \\
\text { trend } \\
(2008-2025)\end{array}$ & $\begin{array}{l}10 \% \\
\text { reduction in } \\
\text { trade costs } \\
(2008-2025)\end{array}$ & $\begin{array}{l}\text { Removal of } \\
\text { cross-border } \\
\text { trade barriers } \\
(2008-2025)\end{array}$ & $\begin{array}{l}\text { 10\% increase } \\
\text { in crop yields } \\
(2008-2025)\end{array}$ \\
\hline ECOWAS & 0.345 & 0.33 & 0.323 & 0.354 & 0.378 \\
\hline COMESA & 0.682 & 0.55 & 0.505 & 0.551 & 0.449 \\
\hline SADC & 0.73 & 0.126 & 0.131 & 0.173 & 0.151 \\
\hline
\end{tabular}

Source: Authors calculations from TradeMaps database and EMM model simulation results

\footnotetext{
${ }^{5}$ In the SADC case, baseline and historical trends of the trade volatility deviate a lot. The main explanation is that, unlike traditional CGE models where countries are exporters or importers from the beginning and remain as such for the length of the simulation period, our model allows countries to enter or exit the regional export market based on relative prices. Therefore, we have used historical production as opposed to trade data to calibrate the model, given that not all countries have historical trade data. The baseline volatility of trade flows is therefore not a result of calibration but rather derives from the calibrated baseline production and its induced trade flows. The SADC region, unlike other regions, has undergone a major structural change in terms of the composition and source of production and thus trade of agricultural products, with Angola, a new player, emerging as the most important trading partner and roots and tubers as the single most important traded agricultural commodity. The projected overwhelming dominance of the more stable Angola in regional production and trade under continuation of current trends is the main explanation of the drop in baseline export volatility.
} 
Table 16.5 Change in regional trade volatility under alternative scenarios (2008-2025)

\begin{tabular}{l|l|l|l|l}
\hline & & $\begin{array}{l}10 \% \text { reduction in } \\
\text { trade costs }\end{array}$ & $\begin{array}{l}\text { Removal of } \\
\text { cross-border trade } \\
\text { barriers }\end{array}$ & $\begin{array}{l}10 \% \text { increase in } \\
\text { crop yields }\end{array}$ \\
\hline \multicolumn{5}{l}{ Baseline trend } \\
\hline Absolute point change compared to historical trend \\
\hline ECOWAS & -0.015 & -0.022 & 0.009 & 0.033 \\
\hline SADC & -0.132 & -0.178 & -0.132 & -0.234 \\
\hline
\end{tabular}

Source: Authors calculations from TradeMaps database and EMM model simulation results

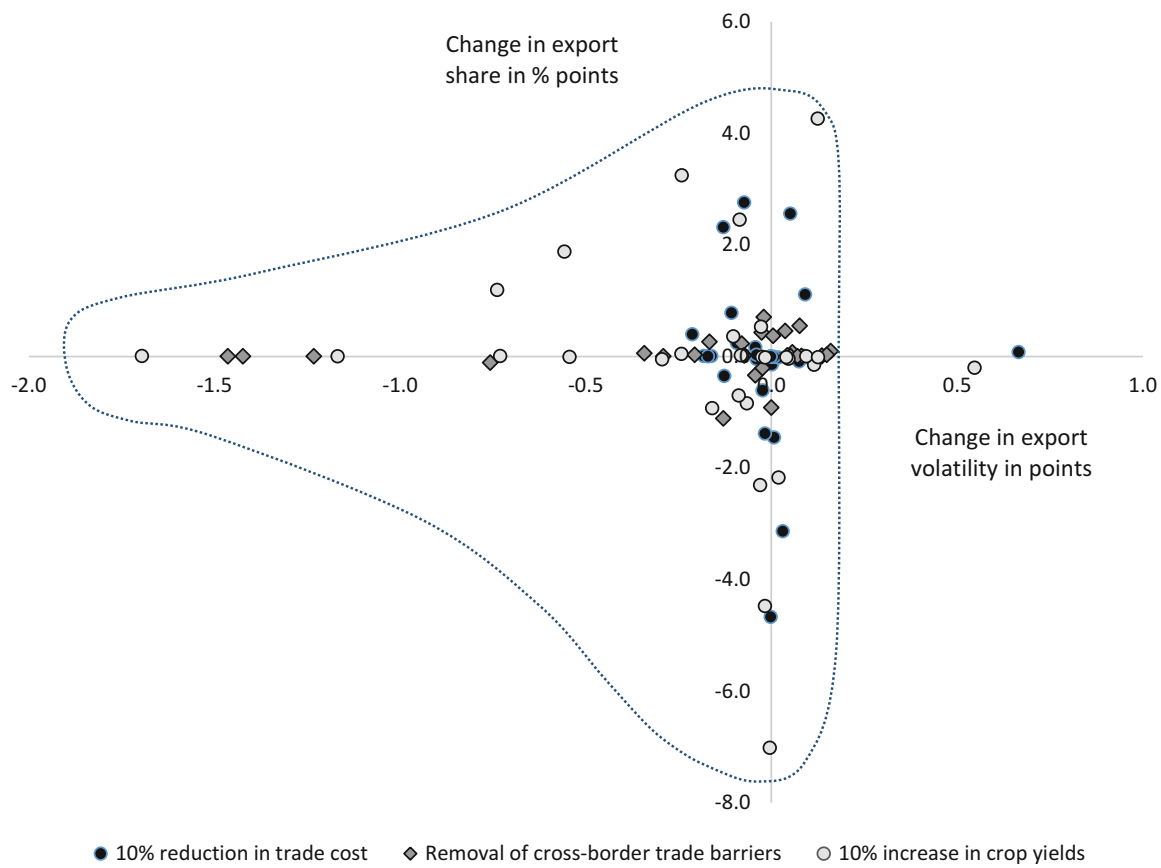

Fig. 16.7 Changes in country export shares and volatility compared to baseline trends

are removed or when yields are increased. The magnitude of changes are, however, rather small across all three scenarios. The figures also show that when the current trend of rising volumes of intra-regional trade continues, volatility levels in all three regions are expected to decline compared to historical trends. A better comparison is therefore to contrast changes that take place under the two trade policy scenarios and the productivity (meaning increasing yields) scenario with the expected volatility levels under the baseline scenario. Furthermore, the direction and magnitude of changes in the level of intra-regional trade volatility are determined by the combined effect of changes in the level of volatility as well as changes in the share of crossborder exports in individual countries. Figure 16.7 above shows changes in volatility 
levels (x-axis) and shares of exports (y-axis) by individual countries under each of the scenarios when compared with the baseline. The different dots indicate the position of different countries under the three scenarios. The tilted distribution of country positions to the left of the x-axis indicates that most countries' exports would experience a lower level of volatility.

The combined changes in export share and volatility for individual countries under each of the scenarios are reported in Table 16.7 and presented in Figs. 16.8, 16.9, 16.10 in the Annex. Only countries that have historically exported are considered. Changes in a country's production patterns resulting from the simulated policy actions lead to changes in both the volatility and the level of exports,and hence the shares in regional trade of each country. The magnitude and direction of these changes determine the contribution of individual countries to changes in the volatility level in regional food markets.

\subsection{Conclusions}

The current chapter has examined the potential to use increased intra-regional trade among Africa's main regional economic communities as a means to raise the resilience of domestic food markets to shocks across their member countries. The distribution and correlation of production volatility as well as the current patterns of specialization in the production and trade of agricultural products among African countries suggest that it is indeed possible to raise cross-border trade to reduce the level of instability of local food markets. The results of the baseline scenario indicate that continuation of recent trends would sustain the expansion of intra-regional trade flows in all three regions, particularly in the ECOWAS region. The findings also reveal that it is possible to significantly boost the pace of regional trade expansion, which in turn would contribute to creating more resilient domestic food markets through modest reduction in the overall cost of trading, a similarly modest increase in crop yields, or the removal of barriers to transborder trade. More importantly, the simulation results also suggest that such policy actions to promote transborder trade would reduce volatility in regional markets and help lower the vulnerability of domestic food markets to shocks. 


\section{Appendix}

Table 16.6 GDP and agricultural growth rates under baseline and recent trends

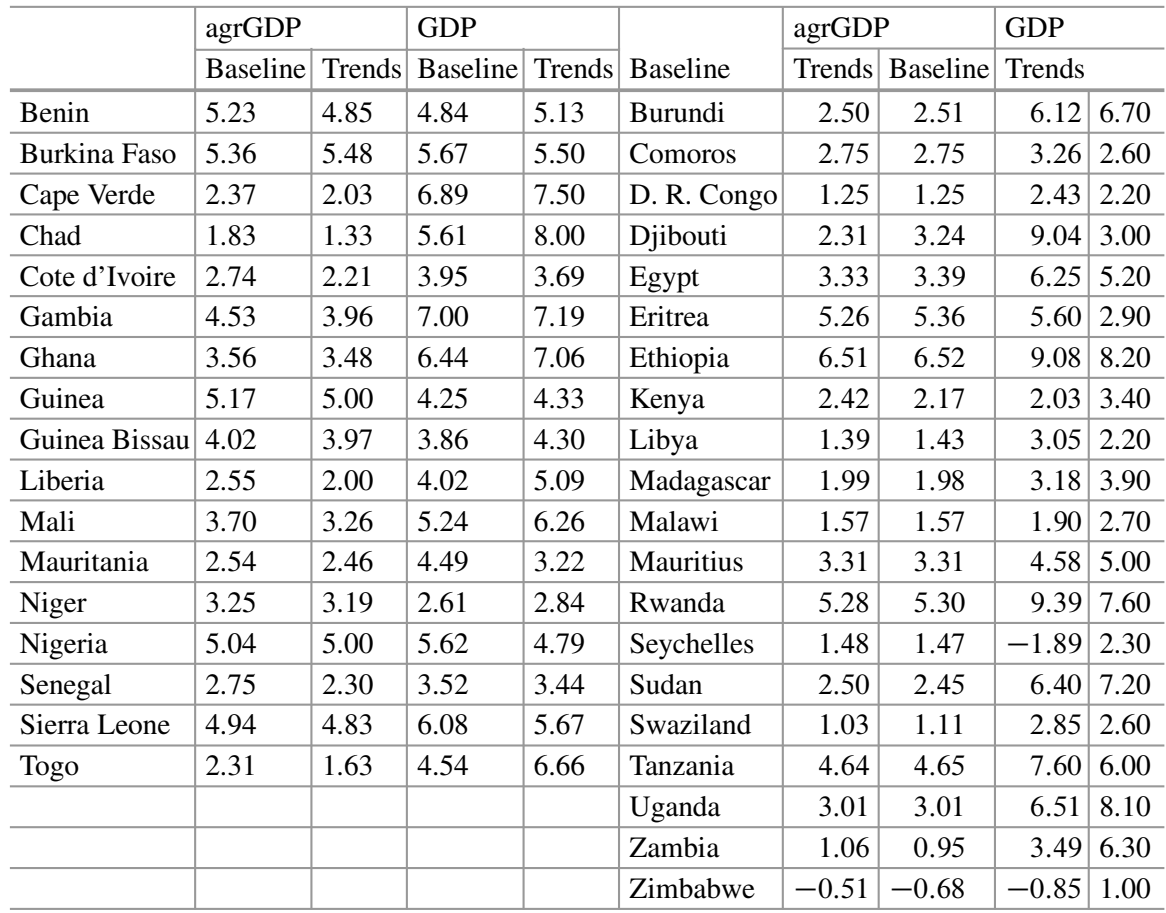

Source: Authors' calculations

Table 16.7 Change in volatility and share of staple exports under alternative scenarios, 20082025

\begin{tabular}{|c|c|c|c|c|c|c|}
\hline & \multicolumn{3}{|c|}{$\begin{array}{l}\text { Change in volatility compared to } \\
\text { baseline (points) }\end{array}$} & \multicolumn{3}{|c|}{$\begin{array}{l}\text { Change in share compared to } \\
\text { baseline (\% points) }\end{array}$} \\
\hline & $\begin{array}{l}10 \% \\
\text { reduction } \\
\text { in trade } \\
\text { cost }\end{array}$ & $\begin{array}{l}\text { Removal } \\
\text { of cross- } \\
\text { border } \\
\text { trade } \\
\text { barriers }\end{array}$ & $\begin{array}{l}10 \% \\
\text { increase } \\
\text { in crop } \\
\text { yields }\end{array}$ & $\begin{array}{l}10 \% \\
\text { reduction } \\
\text { in trade } \\
\text { cost }\end{array}$ & $\begin{array}{l}\text { Removal } \\
\text { of cross- } \\
\text { border } \\
\text { trade } \\
\text { barriers }\end{array}$ & $\begin{array}{l}10 \% \\
\text { increase } \\
\text { in crop } \\
\text { yields }\end{array}$ \\
\hline Benin & -0.073 & -0.043 & -0.085 & 2.756 & -0.338 & 2.448 \\
\hline Burkina Faso & -0.213 & 0.077 & -0.027 & 0.398 & 0.545 & 0.530 \\
\hline Ivory Coast & -0.126 & -0.026 & -0.066 & -0.351 & 0.428 & -0.843 \\
\hline Gambia & -0.039 & -0.206 & -0.294 & -0.047 & 0.026 & -0.052 \\
\hline Ghana & -0.023 & -0.079 & -0.088 & -0.609 & 0.227 & -0.704 \\
\hline Guinea & 0.002 & 0.160 & 0.116 & -0.144 & 0.095 & -0.151 \\
\hline Guinea-Bissau & 0.086 & 0.055 & -0.082 & 0.009 & 0.005 & 0.016 \\
\hline
\end{tabular}


Table 16.7 (continued)

\begin{tabular}{|c|c|c|c|c|c|c|}
\hline & \multicolumn{3}{|c|}{$\begin{array}{l}\text { Change in volatility compared to } \\
\text { baseline (points) }\end{array}$} & \multicolumn{3}{|c|}{$\begin{array}{l}\text { Change in share compared to } \\
\text { baseline ( } \% \text { points) }\end{array}$} \\
\hline & $\begin{array}{l}10 \% \\
\text { reduction } \\
\text { in trade } \\
\text { cost }\end{array}$ & $\begin{array}{l}\text { Removal } \\
\text { of cross- } \\
\text { border } \\
\text { trade } \\
\text { barriers }\end{array}$ & $\begin{array}{l}10 \% \\
\text { increase } \\
\text { in crop } \\
\text { yields }\end{array}$ & $\begin{array}{l}10 \% \\
\text { reduction } \\
\text { in trade } \\
\text { cost }\end{array}$ & $\begin{array}{l}\text { Removal } \\
\text { of cross- } \\
\text { border } \\
\text { trade } \\
\text { barriers }\end{array}$ & $\begin{array}{l}10 \% \\
\text { increase } \\
\text { in crop } \\
\text { yields }\end{array}$ \\
\hline Liberia & -0.001 & 0.136 & 0.094 & -0.002 & 0.003 & -0.002 \\
\hline Mali & 0.031 & 0.057 & -0.017 & -3.137 & 0.069 & -4.475 \\
\hline Niger & 0.091 & -0.129 & -0.241 & 1.111 & -1.115 & 3.247 \\
\hline Senegal & 0.019 & 0.137 & 0.126 & -0.020 & 0.014 & -0.016 \\
\hline Sierra Leone & 0.666 & -0.073 & -0.242 & 0.075 & 0.016 & 0.045 \\
\hline Togo & 0.083 & 0.150 & 0.046 & -0.038 & 0.026 & -0.042 \\
\hline Egypt & -0.129 & -0.020 & -0.102 & 2.315 & 0.701 & 0.360 \\
\hline Eritrea & 0.075 & 0.043 & 0.547 & -0.091 & 0.014 & -0.203 \\
\hline Ethiopia & 0.052 & 0.005 & 0.125 & 2.557 & 0.368 & 4.261 \\
\hline Kenya & 0.006 & 0.081 & 0.041 & -0.009 & 0.004 & -0.016 \\
\hline Libya & -0.001 & 0.001 & -0.004 & -4.669 & -0.918 & -7.018 \\
\hline Sudan & 0.007 & 0.037 & 0.020 & -1.456 & 0.453 & -2.175 \\
\hline Angola & -0.043 & -0.024 & -0.030 & 0.165 & -0.210 & -2.306 \\
\hline Botswana & -0.002 & 0.052 & -0.025 & -0.003 & 0.001 & -0.008 \\
\hline Congo, Dem. Rep & -0.182 & -1.232 & -0.730 & 0.004 & 0.000 & 0.006 \\
\hline Madagascar & -0.162 & -1.423 & -1.695 & 0.007 & 0.001 & 0.005 \\
\hline Malawi & -0.107 & -0.757 & -0.557 & 0.781 & -0.114 & 1.876 \\
\hline Mozambique & -0.130 & -1.288 & 6.099 & 0.165 & 0.007 & 0.194 \\
\hline South Africa & -0.017 & -0.166 & -0.159 & -1.382 & 0.258 & -0.927 \\
\hline Swaziland & -0.002 & 0.071 & -0.016 & -0.007 & 0.001 & -0.022 \\
\hline Tanzania & -0.093 & -0.342 & -0.739 & 0.237 & 0.052 & 1.189 \\
\hline Zambia & -0.170 & -1.464 & -1.168 & 0.002 & 0.001 & 0.000 \\
\hline Zimbabwe & -0.039 & -0.290 & -0.543 & 0.030 & 0.003 & -0.008 \\
\hline
\end{tabular}

Source: Based on simulation results using Economy-wide Multimarket Models of ECOWAS, COMESA, and SADC regions 


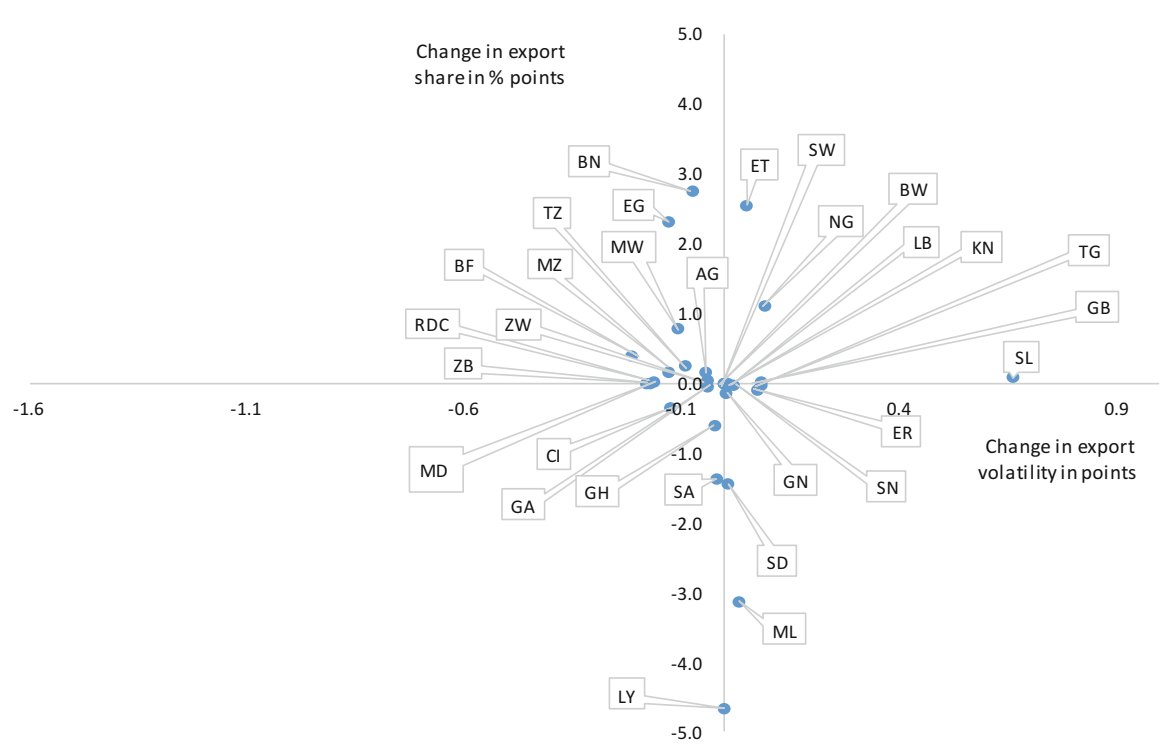

Fig. 16.8 Changes in country export share and volatility under $10 \%$ reduction in trade costs compared to baseline. Source: Based on Table 16.7

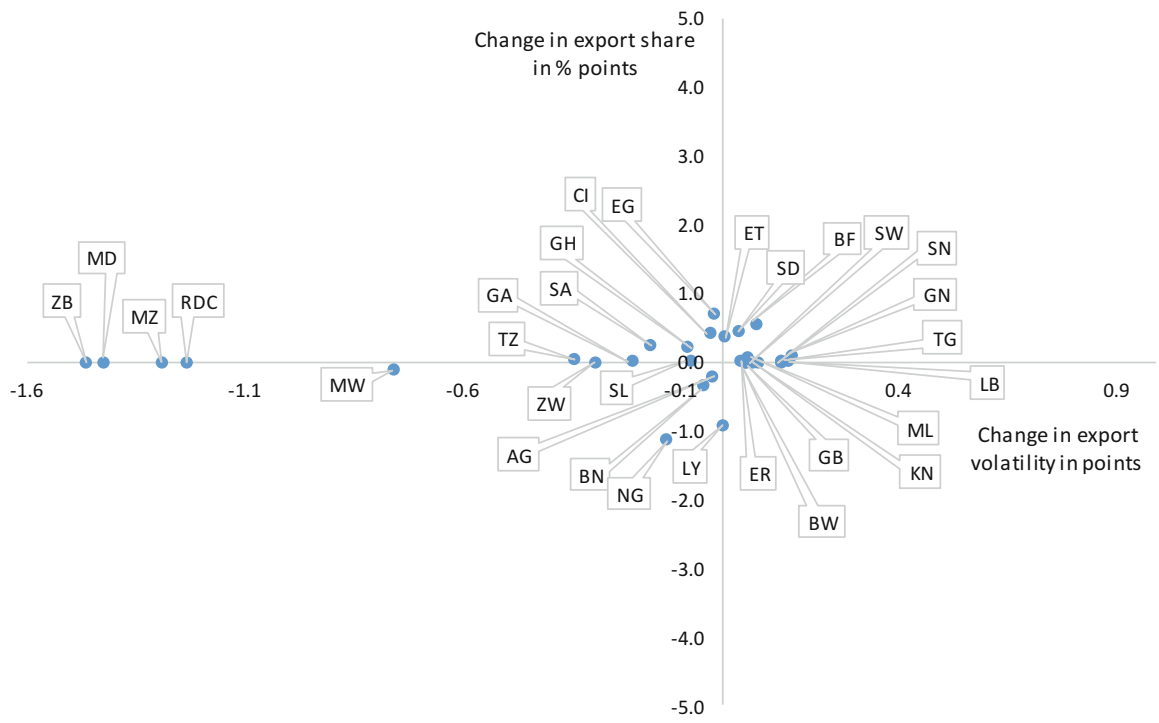

Fig. 16.9 Changes in country export share and volatility under a removal of cross-border trade barriers compared to baseline. Source: Based on Table 16.7 above 


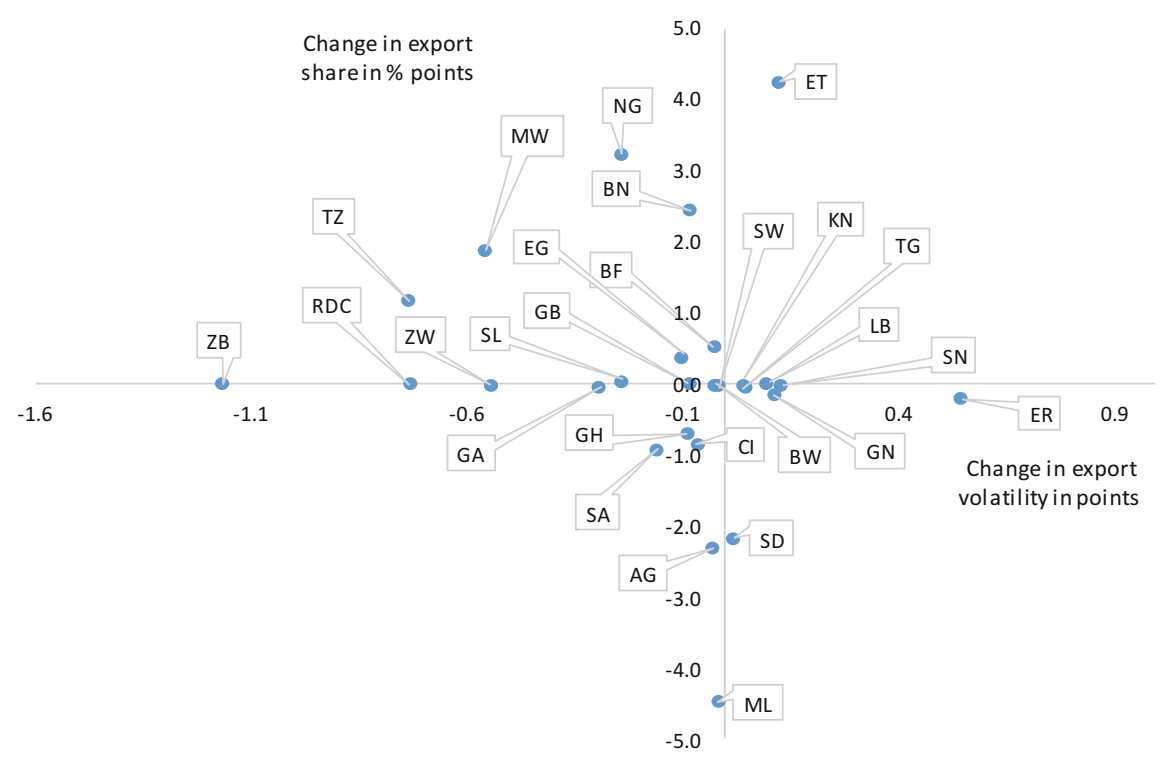

Fig. 16.10 Changes in country export share and volatility under $10 \%$ increase in crop yields compared to baseline. Source: Based on Table 16.7. Note: For the sake of clarity, values for Madagascar and Mozambique, which are too large compared to the rest, are not plotted in the figure

Open Access This chapter is distributed under the terms of the Creative Commons AttributionNoncommercial 2.5 License (http://creativecommons.org/licenses/by-nc/2.5/) which permits any noncommercial use, distribution, and reproduction in any medium, provided the original author(s) and source are credited.

The images or other third party material in this chapter are included in the work's Creative Commons license, unless indicated otherwise in the credit line; if such material is not included in the work's Creative Commons license and the respective action is not permitted by statutory regulation, users will need to obtain permission from the license holder to duplicate, adapt or reproduce the material.

\section{References}

Badiane O, Makombe T, Bahiigwa G (2014) Promoting agricultural trade to enhancing resilience in Africa. Annual trends and outlook report. Regional strategic analysis and knowledge support systems, Washington, DC

Badiane O (1988) National food security and regional integration in West Africa. Wissenschaftsverlag Vauk, Kiel, Germany

Bouët A, Laborde Debucquet D (2015) Global trade patterns, competitiveness, and growth outlook. In: Badiane O, Makombe T, Bahiigwa $\mathrm{G}$ (eds) Promoting agricultural trade to enhancing resilience in Africa. Annual trends and outlook report. Regional strategic analysis and knowledge support systems, Washington, DC

Cuddy JD, Della Valle PA (1978) Measuring the instability of time series data. Oxford Bulletin 44: 78-85 
Diao X, Fekadu B, Haggblade S, Taffesse AS, Wamisho K, Yu B (2007) Agricultural growth linkages in Ethiopia: estimates using fixed and flexible price models. International Food Policy Research Discussion Paper No 00695. IFPRI, Washington, DC

Koester U (1986) Regional cooperation to improve food security in Southern and Eastern African countries. Research Report 53. IFPRI, Washington, DC

Nin-Pratt A, Johnson B, Magalhaes E, You L, Diao X, Chamberlain J (2011) Yield gaps and potential agricultural growth in West and Central Africa. IFPRI, Washington, DC 